\title{
Seepage and settlement monitoring for earth embankment dams using fully distributed sensing along optical fibers
}

\author{
P. Y. Zhu*a, Y. Zhou ${ }^{\mathrm{b}}$, Luc Thévenaz ${ }^{\mathrm{c}}$, G. L. Jiang ${ }^{\mathrm{a}}$ \\ ${ }^{a}$ Hunan provincial Key Laboratory of Health Maintenance for Mechanical Equipment, Hunan \\ University of Science and Technology, Xiangtan China 411201; $\quad{ }^{b}$ Research Centre on Levee \\ Safety \& Disaster Prevention Ministry of Water Resources, Zhengzhou China 450003 ; $\quad{ }^{\circ}$ EPFL \\ Swiss Federal Institute of Technology, Institute of Electrical Engineering, STI-GR-SCI Station 11, \\ 1015 Lausanne, Switzerland
}

\begin{abstract}
A method for seepage and settlement monitoring in earth embankment dams using fully distributed sensing along optical fibres is proposed. A model is developed for simulating and monitoring seepage and settlement systems. This model relates the strains and the temperature changes to the fiber Brillouin gain spectrum in the embankment dam embedding the optical fiber sensors. The model consists of two parts. Submodel 1 addresses the simulation of seepage inside the embankment dam. Submodel 2 relates the measurement of the fiber Brillouin gain spectrum to the changes in temperature and strain inside the embankment dam. Both the changes in temperature and strain during the process are used to reveal serious seepages and settlements occurring inside the embankment dam. The continuously decreasing temperature curve shows an abrupt dramatic increasing rate, which shows that the change is not caused by the temperature of the seepage water but the strain. In this paper, as an example, a model filled with the soil from Yellow River is built and bare optical fibers are embedded under different soil layers near the seepage path. The simulated seepage flows under various flow rates are monitored using the optical fibers and measured by a DiTeSt -STA202 distributed temperature and strain analyzer. A partial settlement within the embankment dam model is observed.
\end{abstract}

Keywords: embankment dam, seepage flow, settlement, optical fiber sensing, temperature and strain

\section{INTRODUCTION}

Embankment dams are designed to remain functional despite some acceptable steady seepage. The background task for the surveillance of an embankment dam is to monitor the changes in temperature and pressure inside the embankment dam induced by those anomalous seepages which may threaten the structure integrity. Water pressure, which is usually detected with some borehole tubes distributed along a possible seepage path, is a traditional quantity being monitored for tracking a seepage flow [1]. Temperature can normally be easily measured in the standpipe using thermometers. Resistivity measurements are comparably more complicated since they require a computer-based monitoring system and minor technical installations on the dam. In spite of the effectiveness of those existing methods, none of them is suitable for continuous monitoring. With the recent advances in optical fiber sensing technology, seepage monitoring systems measuring the temperature inside the embankment dam using distributed sensing along optical fibers have been developed [2]. A preheated optical cable method is used in the dam filled with concrete core to detect seepage flow. The sensing cable is embedded at the dam toe filled with earth for the temperature measurement and other independent cables are installed at other places for the strain measurement [3]. Any excessive and unexpected seepage may lead to the failure of the embankment dam, especially in unconsolidated terrains, such as earth-filled embankment dams. However, if temperature and strain values are recorded separately, which is difficult for an early warning of the settlement in the embankment dam caused by serious seepage or piping. Moreover, the temperature change due to the seepage may become relatively stable when a higher seepage rate flow finds a fixed path through the embankment dam. Nevertheless, in dangerous cases such as those massive quake-induced lakes in China in 2008, the ability of the embankment to maintain itself under high stress needs to be investigated, since it is the main reference information for the crucial decision to either destroy the embankment dam, or to sluice by a diversion facility, or to reinforce the embankment dam to prevent an unexpected dam-break in the weaken parts.

2008 International Conference on Optical Instruments and Technology: Optoelectronic Measurement Technology and Applications, edited by Shenghua Ye, Guangjun Zhang, Jun Ni, Proc. of SPIE Vol. 7160

$716013 \cdot$ ? 2009 SPIE · CCC code: 0277-786X/09/\$18 - doi: 10.1117/12.811964

Proc. of SPIE Vol. 7160 716013-1 
In this paper, a method for seepage monitoring in earth embankment dams using fully distributed sensing along optical fibers is proposed. Both the changes of temperature and strain during the process are exploited to reveal serious seepage and settlement occurring inside the embankment dam. As validation a model filled using real Yellow River soil is built and bare optical fibers are embedded under different layers to identify and compare the quantities at different distance away from the seepage flow. The simulated seepage flows under various flow rates are monitored along optical fibers used as linear sensing elements and a DiTeSt -STA202 distributed temperature and strain analyzer for collecting and processing data. Experimental results are presented, showing a good agreement with direct observations in a vertically cut plane along the simulated seepage path after the model is excavated.

\section{THEORETICAL ANALYSIS}

Seepage can emerge at any location on the downstream face through the seepage line. If the seepage forces are large enough, the soil will be eroded from the foundation and be deposited in a cone-shaped surface near the outlet. The appearance of these "boils" is an evidence of a muddy seepage flow carrying soil particles. This shows the onset of piping and a complete failure of the dam may occur within hours. The thermohydraulic behavior and soil mechanics are complex during this process. The embankment dam can collapse at any moment and the responsibility over the community is serious for the owner. Hence, effective early warning of a serious seepage - that may even turn into a collapse or a landslide - is necessary and the practical information is crucial to ensure the safety of the embankment dam. Both temperature changes and pressure rises in saltation around the seepage path must be monitored as completely as possible.

There are three kinds of basic thermal processes, heat conduction from the embankment crest and from the foundation due to geothermal flow, advection and radiation [4]. The first two processes are partially coupled to each other because viscosity and density are temperature-dependent. The initial temperature of the seepage flow is close to the water temperature in the river or reservoir, which makes the inner temperature in the embankment dam rise or fall by simple soil warming or cooling. Conversely, from the point of view of heat transfer, the temperature of the seepage flow will fall by the impact of heat dissipation while penetrating through the embankment dam. All embankment dams experience some seepage as the impounded water seeks for paths of least resistance through the dam and its foundation. When a lot of water rushes into the embankment dam through the already existing seepage paths, especially when a so-called piping occurs, the seepage may result in the settlement of the saturated embankment dam. Despite the apparent rising of both the velocity and the quantity of seepage flow, they turn out to be difficult to measure directly. However, it is comparatively easier to measure an abrupt stress change of the soil around the settlement.

The energy flux consists of heat conduction in the solid phase and in the water, heat advection through the average leakage water flow, and dispersion due to variability in the leakage water flow velocities. An energy balance equation can be written [5]:

$$
C_{0} \frac{\partial T}{\partial t}=\frac{\partial}{\partial x_{i}}\left(\kappa \frac{\partial T}{\partial x_{i}}-C_{w} T q_{i}-Q_{i}^{d i s p}\right)
$$

where $C_{0}$ is the volumetric heat capacity of thin sand, $\mathrm{J} / \mathrm{m}^{3} \mathrm{k} ; C_{w}$ is the volumetric heat capacity of water, $\mathrm{J} / \mathrm{m}^{3} \mathrm{k} ; Q_{i}^{\text {disp }}$ is the energy flux due to mechanical and thermal dispersion, $\mathrm{J} / \mathrm{m}^{2} \mathrm{~s} ; q_{i}$ is the leakage flow (Darcy seepage), $\mathrm{m} / \mathrm{s} ; T$ is the temperature, ${ }^{\circ} \mathrm{C} ; t$ is the time, $\mathrm{s} ; x_{i}$ is the coordinate, $\mathrm{m} ; \kappa$ is the thermal conductivity of thin sand, $\mathrm{W} / \mathrm{mk}$.

The water temperature in the seepage flow is different from pore water and acts as a tracer, but it propagates at thermal velocity instead of pore velocity. Tracers can not be assumed to be conservative quantities here. So the general equation of seepage water can be described by Darcy law:

$$
q_{i}=-\frac{k_{i j}}{\mu}\left(\frac{\partial p}{\partial x_{j}}+\rho_{f} g_{i}\right)
$$

where $K_{i j}$ is the permeability, $\mathrm{m}^{2} ; \mu$ is the dynamic viscosity, $\mathrm{kg} / \mathrm{ms} ; p$ is the pressure, $\mathrm{N} / \mathrm{m}^{2} ; g_{i}$ is the gravity, $\mathrm{m} / \mathrm{s}^{2}$. 
From Equation (2), the pressure $p$ increases when the leakage flow rises. This is the motivation to detect pressure using traditional borehole pressure tube installed around the seepage line.

\section{EXPERIMENTAL VERIFICATION}

In order to investigate the strain and temperature change inside the embankment dam during the seepage and while settlement in the surface occurs, a bare optical fiber sensor is installed to monitor the two quantities while simulations are simultaneously carried out using a specially designed simulation kit. It turns out to be quite easy and flexible to monitor the signal without long waiting and difficulty to seek for and track a serious seepage flow in the real embankment dam. The boundary conditions can be modified to explore the relationship between the seepage flow and the settlement.

\section{Experimental setup}

As shown in Fig.1, the embankment dam model and simulator kit to simulate the seepage flow is made of: a water tank, a water control valve, the embankment dam model itself and water input port components. The embankment model is filled with real soil from the Yellow River embankment dam in Zhenzhou. The measurement system consists of a DiTeSt-STA202 analyzer, optical fiber sensors and some connection accessories.

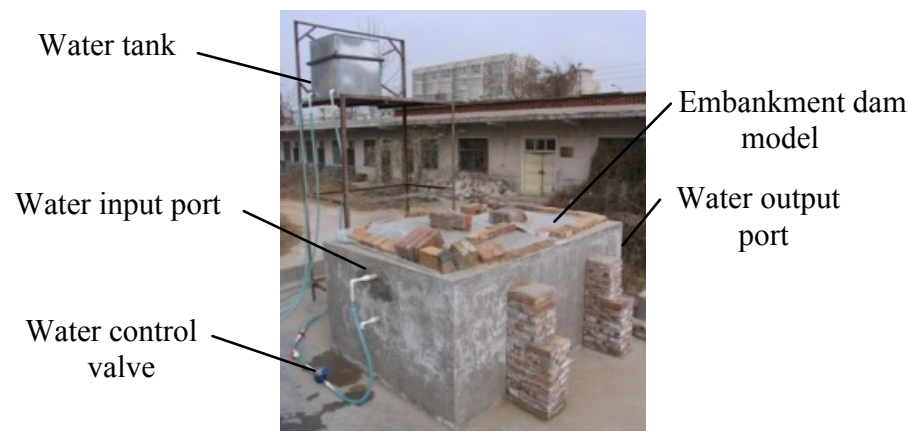

Fig.1. Seepage simulator kit

\subsection{Configuration of the optical fiber sensing system}

The optical fiber sensing system is based on the mechanism of Stimulated Brillouin Scattering (SBS) in single mode optical fibers. By monitoring the Brillouin gain of the probe light in frequency domain, one can detect the temperature and strain along optical fibers around which the abnormal seepage and the settlement occur. The optical fiber sensors are embedded in four different layers inside the embankment dam model (size $2 \mathrm{~m} \times 1.2 \mathrm{~m} \times 2 \mathrm{~m}$ ) to measure the effect of temperature and strain. The sensors are distributed along different temperature contour lines in the seepage flow, as shown in Fig.2. The distances between the four layers are $0.1 \mathrm{~m}$ (sensor \#1), $0.2 \mathrm{~m}$ (sensor \#2), $0.3 \mathrm{~m}$ (sensor \#3), and $0.35 \mathrm{~m}$ (sensor \#4) above the bottom of the embankment dam model, respectively. Fig.2 shows a view of the vertical plane along the seepage path inside the embankment dam model.

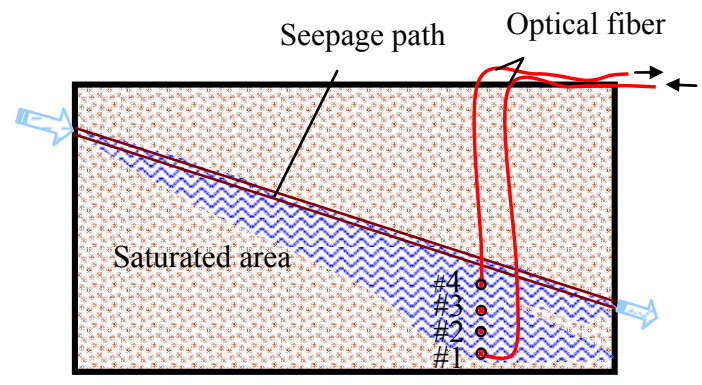

Fig.2. The configuration of optical fiber sensors 
The internal laser source of the DiTeSt-STA202A propagates successively through sensor \#1, sensor \#2, sensor \#3, and finally sensor \#4 to eventually return to the analyzer. Fig.3 shows the transverse intersection plane where all the optical fiber sensors are placed.

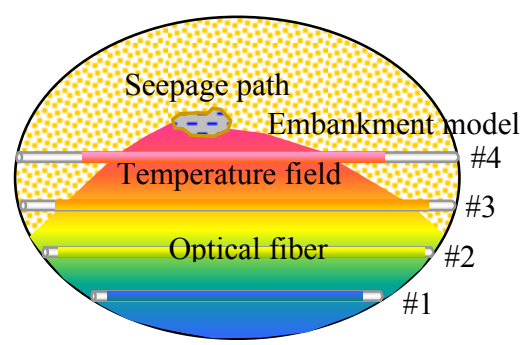

Fig.3. Intersection plane where optical fiber sensors locate

\subsection{Experiments of seepage flow monitoring}

\subsubsection{Case 1: saturating the embankment dam model with water}

Once the embankment dam model equipped with the optical fibers is set up and ready to use, a zincificated steel tube embedded in advance inside the model was pulled out quickly. The iced-water in the tank enters into the embankment dam model through the external water pipe and flows into the seepage path. This latter was previously pre-formed using the zincificated steel tube to saturate the soil in the embankment dam model. The signal is continuously measured during the saturating process. The water flux is controlled using a water control valve. One day later, the seepage path around the man-made water drainage routeway is assumed to be formed. Some new ice blocks were placed into the water tank and a considerably larger quantity of iced water was poured into the embankment dam model through the same water input port (see Fig.1). The rate at which the entered water percolates in soils may have a considerable impact on the kinetics of transport processes of the seepage and the soil. The water flux is gradually increased to simulate further huge seepage after the seepage flow is in an observable steady state for a moment. This situation defines the moment to create an agenda to perform periodic executions of the measurement routine. An automatic measurement can be performed according to a pre-defined measurement agenda. The temperature of the soil inside the embankment dam model and the temperature of the water in the water tank are measured using traditional thermometers. The ice blocks are added into the water tank to cool the water, since this facilitates the observation of apparent differences between the original temperature and the actual temperature inside the embankment dam model. Three kinds of flux are chosen in the experiments.

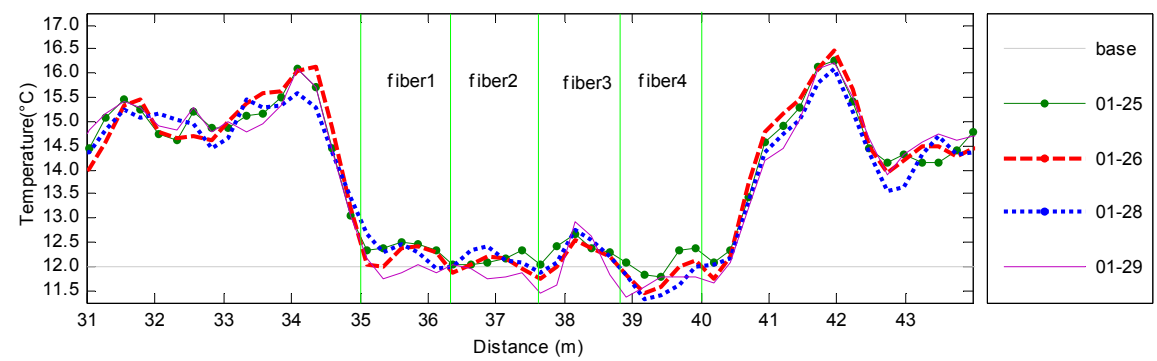

Fig.4. Initial stage of the optical fibers outside and inside the embankment dam model 


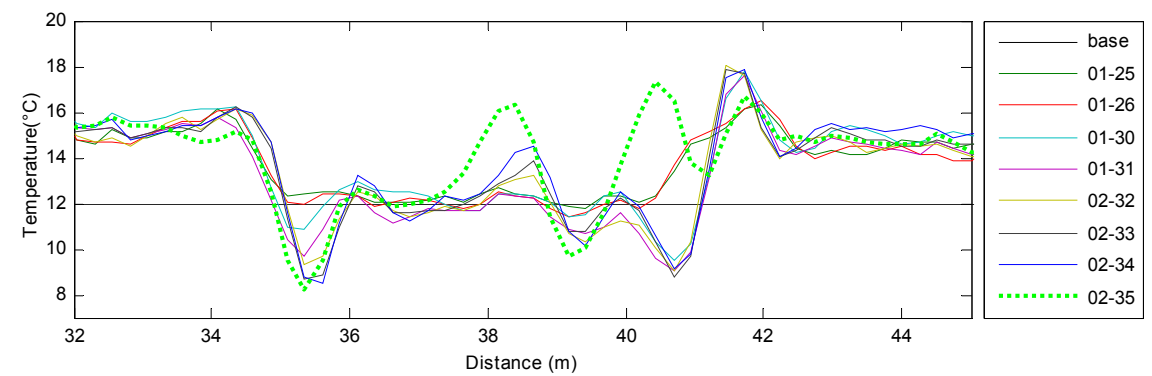

Fig.5. Temperature change process during pouring into cold water (01-25 and 01-26 are temperatures curve before pouring into cold water; 02-34 is the last temperature curve before huge strain appears, blue line; 02-35 is the first strain curve, green dotted line)

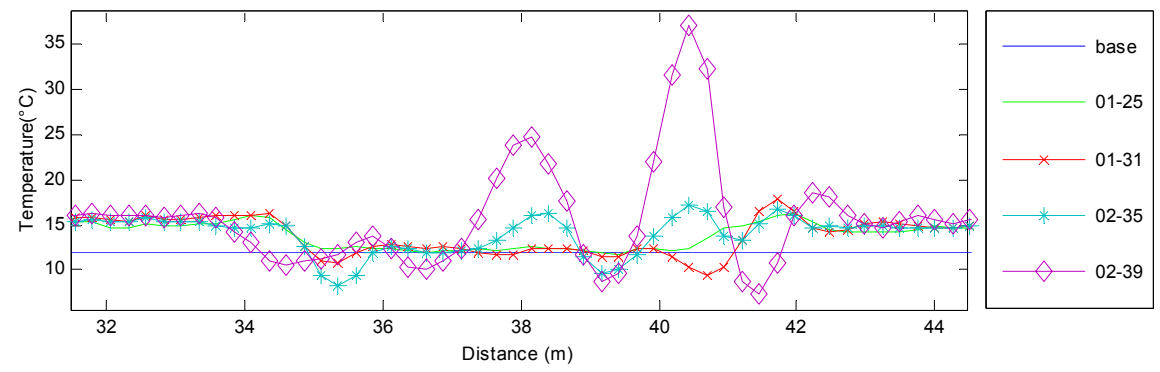

Fig.6. Three turning curves of the temperature and the strain (01-25 is the temperature before pouring into cold water, solid line; 01-31 is the first reduced temperature curve, line with cross marked; 02-35 is the first strain curve, line with asterisk marked; 02-39 is the maximum strain curve in the experiments, line with diamond marked.).

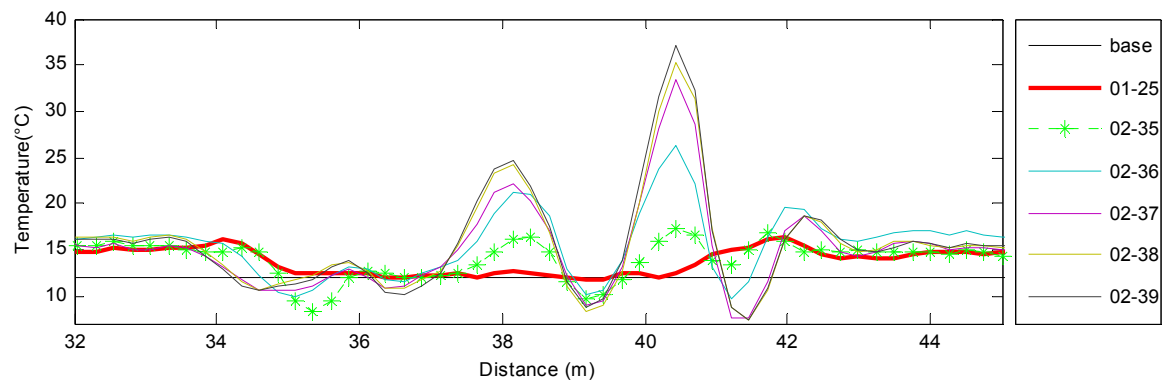

Fig.7. Turning curves of the temperature and strain curves during the process of strain increase

The temperature inside the embankment dam model changes while the water is pouring into the embankment dam model. It is shown in Fig.4, presenting the initial condition of the optical fibers outside and inside the embankment dam model. We can see that outdoor temperature is around 15 degrees; Initial temperature inside the embankment dam model is 12 degrees.

The two temperatures keep stable for a moment before the coming of the next relatively large water flow. The next day, when the flux of pouring water increases, the temperature inside the embankment dam model gets down since some new ice blocks are mixed into the water in the tank again. It is noticed that the curve "02-34" (blue solid line in Fig.5) is the lowest temperature curve. The curve "02-35" (green dotted line in Fig.5) is the turning point curve of large strain caused by the settlement in the embankment dam model. The increased value of Brillouin frequency shows that the settlement occurs from that moment (curve "02-35"). Moreover, all values of the Brillouin frequency along the optical fiber have increased. Until completion of the experiment, the values of the Brillouin frequency keep steadily increasing. The three turning point curves are shown in Fig.6. 01-25 is the temperature before pouring into cold water, solid line; 01-31 is the 
first reduced temperature curve, line with cross symbols; 02-35 is the first strain curve, line with asterisk symbols; 02-39 is the maximum strain curve in the experiments, line with diamond symbols.

After the seepage flow turns stable, the temperature of the water in seepage flow impacts less the temperature of the soil around the seepage path. Serious and continuous seepage flow will result in the settlement of the embankment dam model. Fig.7 shows the strain changing process with increasing water flux. It is apparently larger at positions of fiber3 and fiber4, located in the higher layers with deeper settlement pit. It must be pointed out that fiber1 and fiber2 experience comparably less strain. It can also be noticed that the strain will get bounded when the deformation extends much, which should be the maximum of the strain. In the experiments, there are four hard side walls to protect the embankment dam model. But for a real embankment dam the settlement develops towards the extreme state where serious dam break/crack may occur. At that moment huge strain are placing the structure beyond the strain threshold that the embankment can endure, which may finally laminate the embankment. It is crucial to capture those turning moments. Although DiTeStSTA202 instrument is designed to analyze one parameter - temperature or strain after setting a calibration using the corresponding coefficient - we have enough proof to believe that the value of Brillouin frequency changed as a result of the strain and not exclusively to the temperature after a large apparent settlement occurs. Fig. 8 shows.

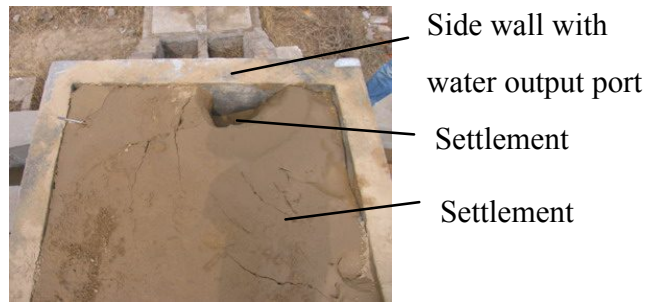

Fig.8. Overall appearance of the embankment dam model with settlement

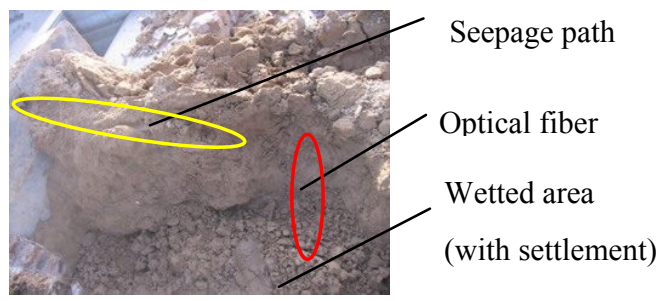

Fig.9. Excavated longitudinal plane with seepage path

a deep settlement pit nearby the water output port and an apparent settlement zone where the optical fiber sensors are placed. To investigate internal conditions in the embankment dam model, this one was excavated along the supposed pre-formed seepage path. The optical fibers can be seen in the wet mud (red circle), and the seepage path does not appear quite clearly (yellow circle), as shown in Fig.9.

\subsubsection{Case 2: direct loading experiment}

To secure a signal change along the optical fiber in a visible and traceable way, a bare optical fiber is placed into the water in a basin. Some ice blocks are added into the water to cool down the water temperature in the basin. The process is similar to the condition prevailing in the embankment dam model. The bare optical fiber is loaded directly by a definite weight, as shown in Fig.10. The signals of both temperature and strain changes are recorded to compare with the results in case 1. The initial temperature of the water in the basin is around 20 degrees. The water temperature in the basin gets down gradually from curve "data3" (red line with asterisk symbols) to curve "data9" (green line with cross symbols) by adding more ice blocks, as shown in Fig.11. The mass block is placed on the support board to load the optical fiber directly. After being loaded by the mass block, the strain applied to the optical fiber increases rapidly. This dramatic change of Brillouin frequency agrees well with the results in case 1. It should be the premonition of possible dam-break. An emergency procedure must be started if this condition is observed. A continuous or sudden drop in the surface of the embankment dam may be an indication that serious seepage and sedimentation is occurring. This condition, in itself, may not be a serious problem, but it will require frequent and close monitoring and further professional assistance. 


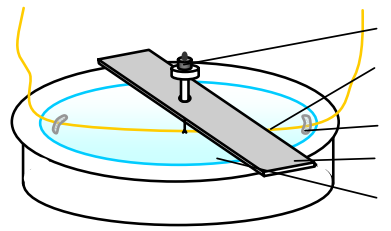

Loading mass

Optical fiber

Fixed sticker

Support board

Water

Fig.10. Experimental setup of direct loading

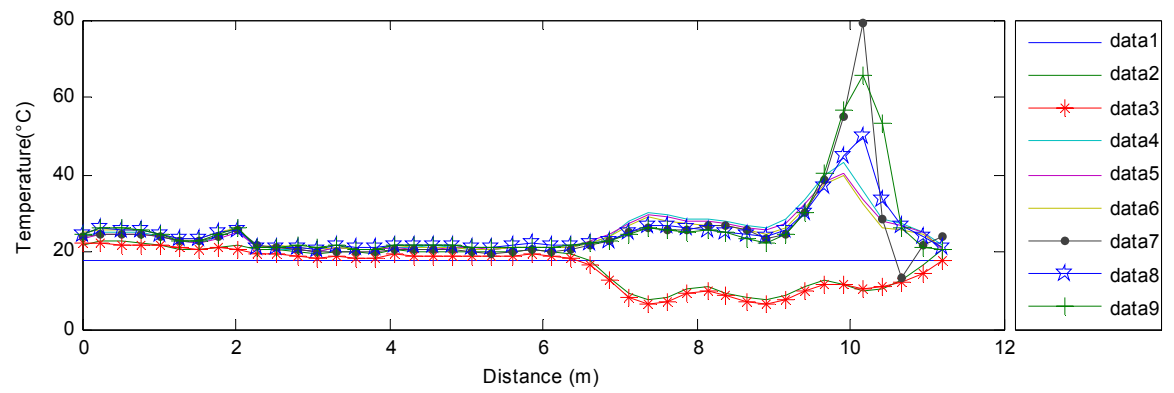

Fig.11. Curves during direct loading on the optical fiber

\section{CONCLUSIONS}

Both the temperature and strain are measured simultaneously while a serious seepage flow occurs. The abrupt change from reduced temperature to huge strain is an important signal to predict the onset of a settlement caused by a serious seepage. This indication does not only concern an early warning action, but also is helpful for making key decision at crucial moments in dangerous dams where collapse may occur at any moment. The possibility to discriminate temperature and strain changes from one optical fiber needs further studies for field applications.

\section{REFERENCES}

[1] Leng Y B, Zhu W Z and He J et al,"Current Situation and Prospects of Dike Anomaly and Infiltration Detecting Technology in China,"Advances in Science and Technology of Water Resources 22(2),59-62(2002).

[2] Thevenaz L, Nikles M, Fellay A, Facchini M and Robert P, "Applications of distributed Brillouin fibre sensing," Proc.SPIE 3407,374-381(1998).

[3] Johansson S and Farhadiroushan M ,"Seepage and strain monitoring in embankment dams using distributed sensing in optical fibres-theoretical background and experiences from some installations in Sweden,"International Symposium on Dam Safety and Detection of Hidden Troubles, Xi'an, China,pg\#(2005).

[4] Zhu P Y, Thevenaz L, Leng Y B and Zhou Y,"Design of simulator for seepage detection in an embankment based on distributed optic fibre sensing technology,"Chinese Journal of Science and Instruments 28(3),431-436(2007).

[5] Johansson S,"seepage monitoring in embankment dams Stockholm," Doctoral thesis,Sweden,pg\#(1997). 